\title{
Using abundance data to assess the relative role of sampling biases and evolutionary radiations in Upper Muschelkalk ammonoids
}

\author{
Alistair J. McGowan and Wolfgang Kiessling \\ Acta Palaeontologica Polonica 58 (3), 2012: 561-572 doi: http://dx.doi.org/10.4202/app.2010.0040
}

The Middle Triassic ammonoid genus Ceratites diversified spectacularly

within the Germanic Muschelkalk Basin during the Anisian/Ladian (244-232

Mya). Previous studies have interpreted this diversification as a sequence of

rapid, endemic radiations from a few immigrant taxa. Here we investigate the

possibility that geological and sampling biases, rather than ecological and

evolutionary processes, are responsible for this pattern. A new specimen-based

dataset of Ceratites species-richness and abundance was assembled. This dataset was combined with 1:200 000 geological maps in a geodatabase to facilitate geospatial analyses. One set of analyses compared species richness per geological map with the number of occurrences and localities per map. Per-map change in the amount of rock available to sample for fossils was also included as a variable. Of these three variables, number of occurrences is the most strongly correlated with richness. Variation in the amount of rock is not a strong determinant of species-richness. However, rarefaction of basin-wide species/abundance data demonstrates that differences in species-richness through time are not attributable to sample size differences. The average percent similarity among sites remained close to 50\% throughout the Upper Muschelkalk. The rank abundance distribution (RAD) of species from the first interval of the Upper Muschelkalk is consistent with colonization of a disturbed environment, while the other two intervals have RADs consistent with more stable ecosystems. These results indicate that genuine ecological and evolutionary events are partly responsible for the observed differences in richness and abundance. Although changes in the RADs through time support changes in the ammonoid assemblage structure, the processes underlying increasing richness and change in RADs cannot be explained by increasing geographic distinctiveness or isolation among the ammonoid assemblages present at different localities.

Key words: Ammonoidea, Ceratites, biodiversity, rank abundance, palaeoecology, Muschelkalk, Triassic.

Alistair J. McGowan [Alistair.McGowan@glasgow.ac.uk], Leibniz Institution for Research on Evolution and Biodiversity at the Humboldt University, Berlin, D-10115, Germany. Present address : School of Geographical and Earth Sciences, University of Glasgow, 
Glasgow, G12 8QQ, UK; Wolfgang Kiessling [Wolfgang.Kiessling@mfn-berlin.de], Leibniz Institution for Research on Evolution and Biodiversity at the Humboldt University, Berlin, D-10115, Germany.

This is an open-access article distributed under the terms of the Creative Commons

Attribution License (for details please see creativecommons.org), which permits unrestricted use, distribution, and reproduction in any medium, provided the original author and source are credited.

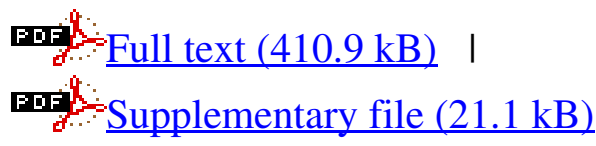

